\title{
Lung transplantation with donation after cardiac death donors: Long-term follow-up in a single center
}

\author{
Nilto C. De Oliveira, MD, ${ }^{\mathrm{a}}$ Satoru Osaki, MD, PhD, ${ }^{\mathrm{a}}$ James D. Maloney, MD, ${ }^{\mathrm{a}}$ Keith C. Meyer, MD, \\ Takushi Kohmoto, MD, PhD, ${ }^{\mathrm{a}}$ Anthony M. D’Alessandro, MD, ${ }^{\mathrm{c}}$ and Robert B. Love, $\mathrm{MD}^{\mathrm{d}}$
}

Objective: We sought to examine long-term outcomes at the University of Wisconsin for all lung transplant recipients who received lungs from donation after cardiac death donors since the initiation of this program in 1993.

\begin{abstract}
Methods: Eighteen (4.2\%) of the 424 lung transplantations performed in 406 patients between January 1993 and April 2009 used lungs from donation after cardiac death donors. Outcomes for this recipient cohort were compared with those for recipients who received organs from brain-dead donors.
\end{abstract}

\begin{abstract}
Results: Warm ischemic time (from withdrawal of support to reperfusion of organs) was $30 \pm 17$ minutes (11-93 minutes). The patient survival rates in the donation after cardiac death group (DCD group) at 1, 3, and 5 years were $88.1 \% \pm 7.9 \%, 81.9 \% \pm 9.5 \%$, and $81.9 \% \pm 9.5 \%$, respectively. These survival rates were not different from those of the brain-dead donor group (BDD group, $P=.66$ ). The incidence of primary graft dysfunction in the DCD group was similar to that of the BDD group $(P=.59)$. However, the incidence of airway complications was somewhat higher in the DCD group. Freedom from bronchiolitis obliterans syndrome at 1,3 , and 5 years in the DCD group was $80.4 \% \pm 10.2 \%, 80.4 \% \pm 10.2 \%$, and $72.3 \% \pm 11.9 \%$, respectively, and did not differ from the incidence of bronchiolitis obliterans syndrome in the BDD group $(P=.59)$.

Conclusions: Our data show that the long-term patient and graft survival rates after donation after cardiac death lung transplantation were equivalent to those after brain-dead donor lung transplantation. Our findings suggest that the use of donation after cardiac death donors can safely and substantially expand the donor pool for lung transplantation. (J Thorac Cardiovasc Surg 2010;139:1306-15)
\end{abstract}

The first successful clinical human lung transplantation (LTx) was performed by Hardy and colleagues ${ }^{1}$ in 1963 using an allograft from a cardiac-arrested donor. Over the ensuing 20 years, a number of transplantations were performed under the same conditions, all without long-term survival. Overall, however, the vast majority of donated organs for clinical LTx were subsequently obtained from brain-dead donors (BDDs). The concept of donation after cardiac death (DCD) LTx has been reintroduced in the laboratory setting by Egan and associates $^{2}$ in 1991 and in the clinical setting with the first successful LTx from a DCD donor into a patient on extracorporeal membrane oxygenation (ECMO) for primary graft dysfunction (PGD) after single-lung transplantation (SLT). ${ }^{3}$

The shortage of donor organs remains the most critical problem in solid-organ transplantation. In an attempt to

From the Department of Surgery, Division of Cardiothoracic Surgery, ${ }^{\mathrm{a}}$ the Department of Medicine, Section of Allergy, Pulmonary, and Critical Care Medicine, ${ }^{b}$ and the Department of Surgery, Division of Transplant Surgery, ${ }^{\mathrm{c}}$ University of Wisconsin School of Medicine and Public Health, Madison, Wis; and the Department of Thoracic and Cardiovascular Surgery, ${ }^{\mathrm{d}}$ Loyola University, Maywood, Ill.

Disclosures: None.

Read at the Eighty-ninth Annual Meeting of The American Association for Thoracic Surgery, Boston, Mass, May 9-13, 2009

Received for publication May 1, 2009; revisions received Jan 12, 2010; accepted for publication Feb 2, 2010.

Address for reprints: Nilto C. De Oliveira, MD, 600 Highland Ave, H4/348 Clinical Science Center, Madison, WI 53792-3236 (E-mail: deoliveira@surgery.wisc.edu). 0022-5223/\$0.00

Published by Elsevier Inc. on behalf of The American Association for Thoracic Surgery

doi:10.1016/j.jtcvs.2010.02.004 solve this problem by increasing the number of donor organs, DCD donors have been used as a source of additional organs. Because of concerns for potential lung injury caused by unavoidable warm ischemia before the initiation of cold flush preservation, DCD lungs have been infrequently used for clinical LTx since the definition of brain death was implemented, even though preclinical experimental evidence has demonstrated the resilience of the lung to warm and cold ischemia. ${ }^{2}$

In nonthoracic organ transplantation clinical studies from several institutions have shown that organs such as the kidney $^{4}$ and liver ${ }^{5}$ obtained from DCD donors can function well after implantation. The Organ Procurement and Transplantation Network data show a progressive increase in the rate of organ recovery from DCD donors (844 DCD donors in 2008 compared with 268 in 2003), and DCD donors accounted for $10 \%$ of all deceased donors in 2007 (http:// optn.transplant.hrsa.gov/). In our own organ procurement organization, the University of Wisconsin Hospitals and Clinics Organ Procurement Organization (UWHC-OPO), DCD donors have accounted for more than $20 \%$ of all deceased donors. The inability to assess the lung visually in situ before arrest has been one obstacle to wider acceptance of use of DCD lungs; however, there continue to be many obstacles to acceptance of lung grafts for transplantation, even for donors meeting standard criteria with the ability perform full evaluation and inspection of organs in situ. Lung use rates remain dismal in the United 


$\begin{array}{ll}\text { Abbreviations and Acronyms } \\ \text { BDD } & =\text { brain-dead donor } \\ \text { BLT } & =\text { bilateral lung transplantation } \\ \text { BOS } & =\text { bronchiolitis obliterans syndrome } \\ \text { DCD } & =\text { donation after cardiac death } \\ \text { ECMO } & \text { extracorporeal membrane } \\ & \text { oxygenation } \\ \text { iNO } & =\text { Inhaled nitric oxide } \\ \text { IQR } & =\text { interquartile range } \\ \text { ISHLT } & =\text { International Society of Heart and } \\ & \text { Lung Transplantation } \\ \text { LAS } & =\text { lung allocation score } \\ \text { LTx } & =\text { lung transplantation } \\ \text { PGD } & =\text { primary graft dysfunction } \\ \text { POD } & =\text { postoperative day } \\ \text { SLT } & =\text { single-lung transplantation } \\ \text { UNOS } & =\text { United Network for Organ Sharing } \\ \text { UWHC-OPO = } & \text { University of Wisconsin Hospitals } \\ & \text { and Clinics Organ Procurement } \\ & \text { Organization } \\ \text { WIT } & =\text { warm ischemic time }\end{array}$

States, about $20 \%$, reflecting a very conservative practice of lung donor evaluation and acceptance.

Mason and coworkers ${ }^{6}$ reported a retrospective review of the outcomes in 36 DCD donor LTx recipients from the United Network for Organ Sharing (UNOS) registry and suggested that the 1-year posttransplantation survival rate of $87 \%$ was equivalent to that after brain death donation. Snell and colleagues ${ }^{7}$ described successful early results in 8 patients receiving transplants from DCD donors. Nonetheless, most publications are limited to small case series reporting the short-term outcomes after DCD donor LTx. ${ }^{7-9}$ According to these reports, the early outcomes of DCD donor LTx (ie, the incidence of PGD and measures of early graft function) are acceptable. However, the longterm results of DCD donor lung recipients, including chronic graft function and the incidence of bronchiolitis obliterans syndrome (BOS), remain unclear. This study analyzed early and late outcomes of recipients who received DCD donor lungs at our institution since the implementation of use of DCD donor lungs was initiated in $1993 .^{3}$

\section{MATERIALS AND METHODS \\ Donor and Recipient Characteristics}

Between January 1993 and April 2009, 424 LTx procedures from deceased donors were performed in 406 patients at UWHC. Among these patients, $18(4.2 \%)$ had lung transplants from DCD donors. The cohorts were divided into the DCD group $(\mathrm{n}=18)$ and the BDD group $(\mathrm{n}=406)$. PGD was defined and graded according to the International Society of Heart and Lung Transplantation (ISHLT) definition (Table 1). ${ }^{10}$ Acute rejection and BOS were also defined by ISHLT criteria. Patient demographics, DCD do- nor characteristics, graft function, posttransplantation complications, and patient and graft survival rates were assessed.

Patient characteristics are listed in Table 2. The proportion of diagnoses was significantly different between the groups $(P=.02)$. In particular, the frequency of retransplantation for graft failure was higher in the DCD group ( $16.7 \%$ in the DCD group vs $3.9 \%$ in the BDD group). Indications for retransplantation for 3 patients in the DCD group were (1) grade 3 PGD requiring ECMO support on postoperative day (POD) 8 after SLT for emphysema, (2) unrelenting graft failure from diffuse alveolar damage 8 months after bilateral lung transplantation (BLT) for idiopathic pulmonary fibrosis, and (3) severe BOS 5 years after SLT for emphysema. The proportion of patients requiring pretransplantation hospitalization exceeding 3 days was significantly higher in the DCD group (33.3\% vs $8.6 \%$, $P<.01)$. The frequencies of the BLT procedure and use of cardiopulmonary bypass were higher in the DCD group. However, there was not a significant statistical difference between the groups. Warm ischemic time (WIT) was defined as the interval between withdrawal of life support and establishing perfusion of the donor lung with cold preservative solution, as described in our previous publications, ${ }^{3-5,11}$ and cold ischemic time was defined as the interval between the cold flush of the donor lung and blood reperfusion of the lung during implantation into the recipient. The mean cold ischemic time was similar in both groups.

\section{DCD Donor Characteristics}

DCD donor characteristics are shown in Tables 2 and 3 . The mean donor age was $30.4 \pm 14.6$ years, and $12(66.7 \%)$ DCD donors were male. The mean age was not different between the groups. The major medical diagnosis was trauma caused by motor vehicle accident in 8 (44.4\%) DCD donors. The median length of mechanical ventilation before withdrawal of support was 4 days, and $7(38.9 \%)$ DCD donors had more than 5 days of ventilator support. Heparin was administered to all DCD donors before withdrawal of support. The mean WIT was $30 \pm 17$ minutes (11-93 minutes). The WIT in 11 (61.1\%) DCD donors was less than 30 minutes.

\section{Selection of DCD Donor Lung Recipients}

The candidates for DCD LTx were determined primarily based on severity of illness and a clinical assessment that the patient would not survive the current condition if required to wait for a standard donor. The transplant surgeon obtained consent for DCD donor LTx with the recipient or legal representative in each case. In the early 1990s, there were no clinical outcome data regarding DCD donor lung grafts, and these lungs were seldom used because of a lack of data about potential lung damage caused by warm ischemia. Therefore the DCD donor lungs were used for the selected patients who were consented for DCD donor lungs and were deemed unlikely to survive while waiting for a transplantation from a BDD because of the rapid deterioration of their end-stage lung disease. These patients were nearly always the sickest patients listed at our center at the time they underwent transplantation.

\section{DCD Donor Program and Evaluation Process in the UWHC-OPO}

Our institution has a long history of using kidneys from controlled DCD donors. ${ }^{4}$ In 1993, our program was expanded to transplantation of extrarenal organs, such as the liver, simultaneous pancreas-kidney, and lung. ${ }^{11}$ Since 2003, the UWHC-OPO has evaluated all referrals of patients with severe brain damage but who do not meet the criteria for brain death and whose families have chosen to withdraw life-sustaining therapies. Because DCD donors frequently have preservation of brain stem reflexes, the possibility of continued respiration and sustained cardiac activity after extubation must be discussed when obtaining consent from the family. Our protocol for donor management and lung retrieval has been refined over the past 15 years and previously published. ${ }^{3-5,11-13}$ When consent is obtained for DCD, the family is informed that multiorgan donation will not occur beyond 2 hours after withdrawal of life support. If cardiopulmonary function persists 
TABLE 1. Criteria for grading of primary graft dysfunction

\begin{tabular}{ccc}
\hline Grade & $\mathbf{P a O}_{2} / \mathbf{F I O}_{2}$ ratio & $\begin{array}{c}\text { Radiographic } \\
\text { infiltrates consistent with } \\
\text { pulmonary edema }\end{array}$ \\
\hline 0 & $>300$ & Absent \\
1 & $>300$ & Present \\
2 & $200-300$ & Present \\
3 & $<200$ & Present \\
\hline
\end{tabular}

Absence of infiltrates on chest radiographic analysis is sufficient for grade 0 , even if the $\mathrm{PaO}_{2} / \mathrm{FIO}_{2}$ ratio is less than 300 . If the subject is on a nasal cannula for oxygen or $\mathrm{FIO}_{2}$ is less than 0.3 , the subject is graded as 0 or 1 based on results of chest radiographic analysis. Any patient on extracorporeal oxygenation is automatically grade 3 . Any subject mechanically ventilated with an $\mathrm{FIO}_{2}$ of greater than 0.5 on nitric oxide beyond 48 hours from the time of transplantation should be considered grade 3 . If multiple blood gas values are available, the worst $\mathrm{PaO}_{2} / \mathrm{FIO}_{2}$ ratio will be used for the purposes of this grading scheme. $\mathrm{PaO}_{2}$, Arterial partial pressure of oxygen; $\mathrm{FIO}_{2}$, fraction of inspired oxygen.

beyond 2 hours after extubation, the patient will be returned to the ward, where they will receive end-of-life care. During the time that consent is obtained, the family is fully informed about the procedure, including any medications that might be given, such as phentolamine and heparin. Once cardiac death is declared by the physician in charge of end-of-life care for the donor, an additional 5 minutes must elapse, as described in the 1997 Institute of Medicine guidelines, ${ }^{14}$ before an incision is made.

\section{Organ Procurement and Preservation}

Our techniques of organ procurement and preservation during DCD have been described. ${ }^{3,11,13}$ When allowed by local hospital DCD protocols, while the patient is fully supported, 30,000 units of heparin and $10 \mathrm{mg}$ of phentolamine are administered intravenously to prevent vasospasm and to facilitate subsequent organ flushing. The patient's physician of record withdraws life support by stopping intravenous medications and extubation. Variable periods of hypotension and hypoxia occur after the withdrawal of life support and before cessation of all cardiopulmonary function. Our current acceptance criteria of WIT for DCD donor lungs is up to 60 minutes; however, one patient in this series had 93 minutes of WIT. Five minutes after the declaration of cardiac death, the donor was reintubated and reventilated by means of hand bagging after suctioning. Median sternotomy is performed, $4 \mathrm{~L}$ of preservative solution is infused in situ through the main pulmonary artery, and $2 \mathrm{~L}$ of retrograde flush is infused through the pulmonary veins. The majority of our donors were perfused with University of Wisconsin Solution, but the last 2 patients received Perfadex (Vitrolife, Göteborg, Sweden) as the preservation solution. The lungs were then stored in preservation solution at $4^{\circ} \mathrm{C}$ and returned to our center. All DCD donor lung organs were recovered by staff surgeons from the UWHC, nearly all by the same surgeon performing the implantation.

\section{Posttransplantation Bronchoscopy and Surveillance}

All lung transplant recipients receive surveillance bronchoscopies with bronchoalveolar lavage and transbronchial biopsies graded according to criteria set by the ISHLT Lung Rejection Study Group ${ }^{15}$ at posttransplantation weeks 2, 6, 12, 18, 26, 40, and 52 to detect rejection, infection, or both. Bronchoscopies are also performed when necessary for clinical indications, with follow-up bronchoscopies performed 4 weeks after a previous bronchoscopy in which acute cellular rejection of any grade was detected. All biopsy results were retrospectively reviewed for this study.

\section{Data Acquisition and Follow-up}

The institutional review board of our institution approved this study. Data were collected prospectively and analyzed retrospectively. The LTx database was reviewed for demographic, operative, perioperative, and out-
TABLE 2. Patient demographics

\begin{tabular}{|c|c|c|c|}
\hline & $\begin{array}{l}\text { DCD group } \\
(\mathbf{n}=\mathbf{1 8})\end{array}$ & $\begin{array}{l}\text { BDD group } \\
(\mathrm{n}=\mathbf{4 0 6})\end{array}$ & $\begin{array}{c}P \\
\text { value }\end{array}$ \\
\hline Age (y) & $46.9 \pm 12.1$ & $50.4 \pm 12.1$ & .20 \\
\hline Sex (female) & $7(38.9 \%)$ & $148(36.5 \%)$ & .81 \\
\hline Race (white) & $18(100 \%)$ & $392(96.5 \%)$ & .89 \\
\hline BMI $\left(\mathrm{kg} / \mathrm{m}^{2}\right)$ & $23 \pm 3.9$ & $24 \pm 4.9$ & .22 \\
\hline Diagnosis & & & .02 \\
\hline COPD/emphysema & $4(22.2 \%)$ & $147(36.2 \%)$ & .23 \\
\hline Cystic fibrosis & $5(27.8 \%)$ & $64(15.8 \%)$ & .19 \\
\hline $\begin{array}{l}\text { Retransplantation for graft } \\
\text { failure }\end{array}$ & $3(16.7 \%)$ & $16(3.9 \%)$ & .04 \\
\hline$\alpha_{1}$-Antitrypsin deficiency & $2(11.1 \%)$ & $47(11.6 \%)$ & $>.99$ \\
\hline $\begin{array}{l}\text { Idiopathic pulmonary } \\
\text { fibrosis }\end{array}$ & $1(5.6 \%)$ & $91(22.4 \%)$ & .14 \\
\hline $\begin{array}{l}\text { Primary pulmonary } \\
\text { hypertension }\end{array}$ & $1(5.6 \%)$ & $5(1.2 \%)$ & .23 \\
\hline Sarcoidosis & $1(5.6 \%)$ & $11(2.7 \%)$ & .41 \\
\hline Lymphangiolyomyomatosis & $1(5.6 \%)$ & $4(1 \%)$ & .20 \\
\hline Other & 0 & $21(5.2 \%)$ & $>.99$ \\
\hline \multicolumn{4}{|l|}{ Pulmonary function } \\
\hline FVC $(\%$ predicted $)$ & $46 \pm 19$ & $48 \pm 17$ & .80 \\
\hline $\mathrm{FEV}_{1}(\%$ predicted $)$ & $26 \pm 9$ & $30 \pm 19$ & .75 \\
\hline $\begin{array}{l}\text { Continuous mechanical } \\
\text { ventilation }\end{array}$ & $2(11.1 \%)$ & $20(4.9 \%)$ & .24 \\
\hline \multicolumn{4}{|l|}{ Hemodynamics } \\
\hline Systolic PAP (mm Hg) & $41 \pm 16$ & $40 \pm 13$ & .74 \\
\hline Mean PAP $(\mathrm{mm} \mathrm{Hg})$ & $30 \pm 13$ & $29 \pm 10$ & .90 \\
\hline PCWP (mm Hg) & $13 \pm 6$ & $14 \pm 8$ & .63 \\
\hline $\begin{array}{l}\text { Cardiac index } \\
\qquad\left(\mathrm{L} \cdot \mathrm{min}^{-1} \cdot \mathrm{m}^{-2}\right)\end{array}$ & $2.9 \pm 0.7$ & $3.0 \pm 0.9$ & .97 \\
\hline Serum creatinine $(\mathrm{mg} / \mathrm{dL})$ & $1.0 \pm 0.3$ & $0.9 \pm 0.5$ & .37 \\
\hline $\begin{array}{l}\text { Pretransplantation } \\
\quad \text { hospitalization } \geq 3 \mathrm{~d}\end{array}$ & $6(33.3 \%)$ & $35(8.6 \%)$ & $<.01$ \\
\hline Time on waiting list (d) & $\begin{array}{c}199 \\
(\mathrm{IQR}, 78-649)\end{array}$ & $\begin{array}{c}240 \\
(\mathrm{IQR}, 93-470)\end{array}$ & .74 \\
\hline $\begin{array}{l}\text { Bilateral lung transplantation } \\
\text { procedure }\end{array}$ & $9(50 \%)$ & $148(36.5 \%)$ & .24 \\
\hline $\begin{array}{l}\text { Cardiopulmonary } \\
\text { bypass }\end{array}$ & $9(50 \%)$ & $138(34 \%)$ & .16 \\
\hline Cold ischemic time (min) & $392 \pm 96$ & $393 \pm 141$ & .59 \\
\hline Donor age (y) & $30.4 \pm 14.6$ & $32.0 \pm 13.2$ & .56 \\
\hline Donor sex (female) & $6(33.3 \%)$ & $139(34.2 \%)$ & .94 \\
\hline Donor race (white) & $18(100 \%)$ & $359(88.4 \%)$ & .31 \\
\hline
\end{tabular}

$\overline{D C D}$, Donation after cardiac death; $B D D$, brain-dead donor; $B M I$, body mass index; $C O P D$, chronic obstructive pulmonary disease; $F V C$, forced vital capacity; $F E V_{I}$, forced expiratory volume in 1 second; $P A P$, pulmonary arterial pressure; $P C W P$, pulmonary capillary wedge pressure; $I Q R$, interquartile range.

come data. Follow-up was obtained through outpatient chart review. The longest follow-up was 5597 days (median of 1380 days and interquartile range [IQR] of 115-1782 days for the DCD group and median of 1269 days and IQR of 419-2569 days for the BDD group).

\section{Statistical Analysis}

Categorical data were summarized with frequency distributions and percentages. The means \pm standard deviations were calculated for variables that were normally distributed, and the medians with IQRs were presented for those that were skewed. Continuous variables were compared by using 
TABLE 3. DCD donor characteristics

\begin{tabular}{ll}
\hline & DCD group \\
\hline Medical diagnosis & \\
Trauma & $8(44.4 \%)$ \\
Cerebrovascular accident & $5(27.8 \%)$ \\
Anoxia & $4(22.2 \%)$ \\
Other & $1(5.6 \%)$ \\
Pulmonary function & \\
Last $\mathrm{Po}_{2} / \mathrm{FIO}_{2}$ ratio & $457 \pm 67$ \\
Length of mechanical ventilation (d) & $4(\mathrm{IQR}, 2-9.5)$ \\
Inotropic support & $6(33.3 \%)$ \\
Pretreatment & \\
Heparin & $18(100 \%)$ \\
Phentolamine & $16(88.9 \%)$ \\
Warm ischemic time from withdrawal to perfusion (min) & \\
Mean & $30 \pm 17$ \\
$10-20$ & $5(27.8 \%)$ \\
$21-30$ & $6(33.3 \%)$ \\
$31-60$ & $6(33.3 \%)$ \\
$\geq 61$ & $1(5.6 \%)$ \\
Organs recovered & \\
Kidney & $18(100 \%)$ \\
Liver & $16(88.9 \%)$ \\
Pancreas & $14(77.8 \%)$ \\
\hline$D C D$, Don &
\end{tabular}

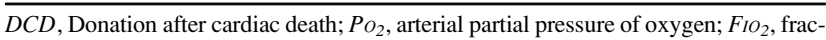
tion of inspired oxygen; $I Q R$, interquartile range.

unpaired $t$ test or the nonparametric Mann-Whitney $U$ test, whereas nominal variables were compared by means of the $\chi^{2}$ or Fisher exact tests, as appropriate. The Kaplan-Meier method was used to assess LTx patient survival, lung graft survival, and freedom from airway complications and BOS. Log-rank tests were used to assess statistical significance in survival differences between the DCD and BDD groups. All analyses were performed with the SPSS statistical software program (SPSS for Windows version 16.0; SPSS, Inc, Chicago, Ill)

\section{RESULTS}

\section{Primary Graft Dysfunction}

Postoperative outcomes are shown in Table 4. The incidence of PGD was not different between the groups. Three $(16.7 \%)$ recipients in the DCD group were given diagnoses of grade 3 PGD within 72 hours after transplantation, but all 3 recovered graft function and were discharged to home. There were no patients who required ECMO support in the DCD group. The incidence of posttransplantation use of inhaled nitric oxide (iNO) was significantly higher in the DCD group $(66.7 \%$ vs $38.9 \%, P=.02)$. However, the frequency of iNO use at 48 hours or later was no different between the groups. Figure 1, $A$, represents the changes in recipients' arterial partial pressure of oxygen/fraction of inspired oxygen ratios for the first 72 hours after LTx. The mean values of partial pressure of oxygen/fraction of inspired oxygen ratios at each time point did not differ between the groups.

\section{Acute Rejection}

The incidence of acute cellular rejection for each grade is shown in Table 4. The frequency of A1 rejection was
TABLE 4. Postoperative outcomes

\begin{tabular}{lccc}
\hline & DCD group & BDD group & $P$ value \\
\hline Primary graft dysfunction & & & .59 \\
Grade 0 or 1 & $12(66.7 \%)$ & $300(73.9 \%)$ & \\
Grade 2 or 3 & $6(33.3 \%)$ & $106(26.1 \%)$ & \\
Required ECMO support & 0 & $26(6.4 \%)$ & .62 \\
$\quad$ Inhalation of nitric oxide & $12(66.7 \%)$ & $158(38.9 \%)$ & .02 \\
$\geq 48$ h of inhalation & $3(16.7 \%)$ & $92(22.7 \%)$ & .77 \\
Reintubation & $2(11.1 \%)$ & $81(20.0 \%)$ & .55 \\
$\quad$ Mechanically ventilated & $1.3(\mathrm{IQR}, 0.9-3.3)$ & $1.8(\mathrm{IQR}, 1.0-4.0)$ & .33 \\
$\quad$ period (d) & & & \\
$\geq 48$ h of ventilator & $6(35.3 \%)$ & $186(47.1 \%)$ & .34 \\
$\quad$ support & $1(5.6 \%)$ & $62(15.3 \%)$ & .49 \\
Reoperation & $1(5.6 \%)$ & $20(4.9 \%)$ & .61 \\
Dialysis & $4(\mathrm{IQR}, 3-8)$ & $6(\mathrm{IQR}, 3-13)$ & .18 \\
Length of ICU stay (d) & $17(\mathrm{IQR}, 15-23)$ & $20(\mathrm{IQR}, 14-33)$ & .43 \\
Length of hospital & & & \\
$\quad$ stay (d) & $1(5.6 \%)$ & $30(7.4 \%)$ & $>.99$ \\
Hospital mortality & $5(27.8 \%)$ & $112(27.6 \%)$ & $>.99$ \\
Readmission $<30 \mathrm{~d}$ & & & \\
Acute rejection* & $5(27.8 \%)$ & $218(53.7 \%)$ & .03 \\
A1 & $6(33.3 \%)$ & $178(43.8 \%)$ & .38 \\
A2 & 0 & $39(9.6 \%)$ & .39 \\
A3 & &
\end{tabular}

$D C D$, Donation after cardiac death; $B D D$, brain-dead donor; $E C M O$, extracorporeal membrane oxygenation; $I Q R$, interquartile range; $I C U$, intensive care unit. *The total number of recipients who experienced each grade of acute rejection during the followup period. At our institution, surveillance bronchoscopies are usually preformed at posttransplantation weeks $2,6,12,18,26,40$, and 52 .

significantly lower $(27.8 \%$ vs $53.7 \%, P=.03)$, and no patients had A3 rejection in the DCD group. Six $(33.3 \%)$ DCD donor recipients experienced acute rejection of $\mathrm{A} 2$ or greater versus $188(46.3 \%)$ recipients in the BDD group. The proportion of acute rejection of grade $\mathrm{A} 2$ or greater tended to be lower in the DCD group $(P=.09)$.

\section{Airway Anastomotic Complications}

Airway anastomotic complications that were observed included bronchial stenosis, dehiscence, excessive granulation tissue formation, and fistulae that required any surgical revision and/or bronchoscopic interventions, such as balloon dilatation, stent replacement, and debridement. During the study period, these complications were observed in 5 $(27.8 \%)$ patients in the DCD group versus $52(12.8 \%)$ in the BDD group $(P=.08)$. One patient in the DCD group had a successful retransplantation of the right lung after a complete dehiscence of the right-sided bronchial anastomosis recognized on POD 12 after a BLT. This was likely due to technical failure at implantation. Four patients had bronchoscopic intervention for bronchial stenosis on POD 38 after SLT, POD 39 after BLT, POD 39 after SLT, and POD 76 after BLT, respectively. The airway complication was associated with Aspergillus species infection of the anastomosis in 2 patients. Freedom from airway anastomotic complications requiring treatment is shown in Figure 2, $A$. The rates of 

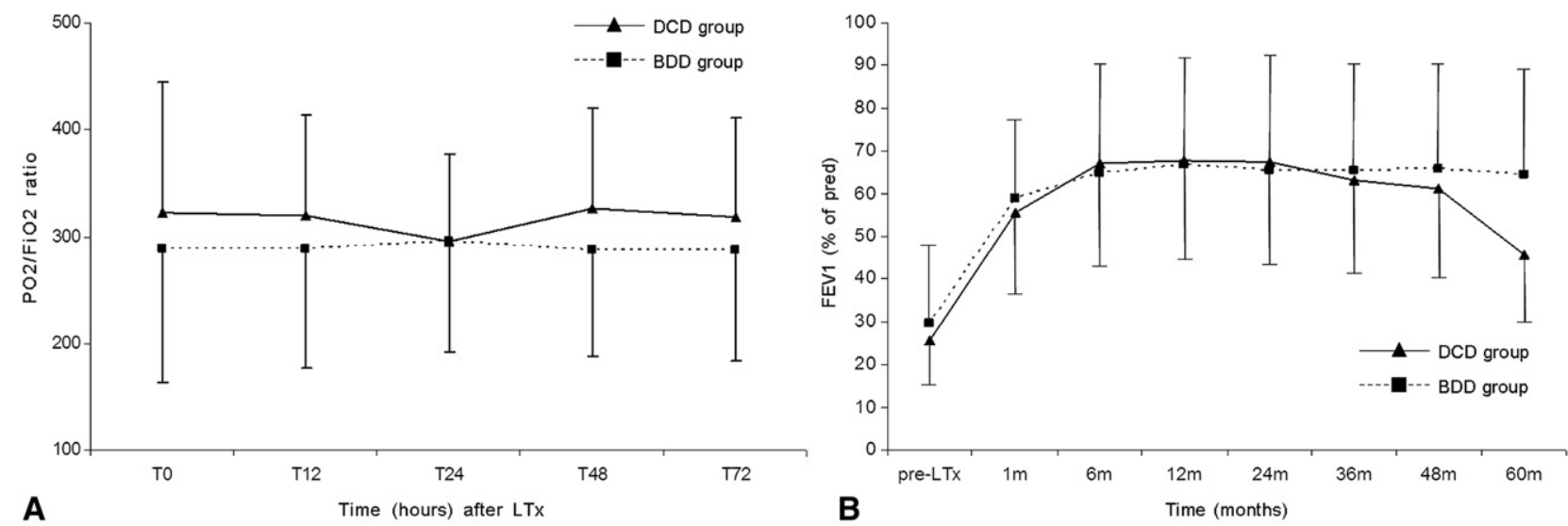

FIGURE 1. Posttransplantation pulmonary function. A, Recipient partial pressure of oxygen $\left(\mathrm{PO}_{2}\right) /$ fraction of inspired oxygen $\left(\mathrm{FIO}_{2}\right)$ ratios for the first 72 hours after lung transplantation $(L T x)$. B, Percent predicted forced expiratory volume in 1 second $\left(F E V_{1}\right)$ after LTx. $D C D$, Donation after cardiac death; $B D D$, brain-dead donor.

freedom from airway complications in the DCD group were significantly lower than those in the BDD group $(P=.02)$.

\section{Chronic Pulmonary Function and BOS}

The changes in percent predicted forced expiratory volume in 1 second during the study period are shown in Figure 1, $B$. The mean values for percent predicted forced expiratory volume in 1 second at each time point did not differ between
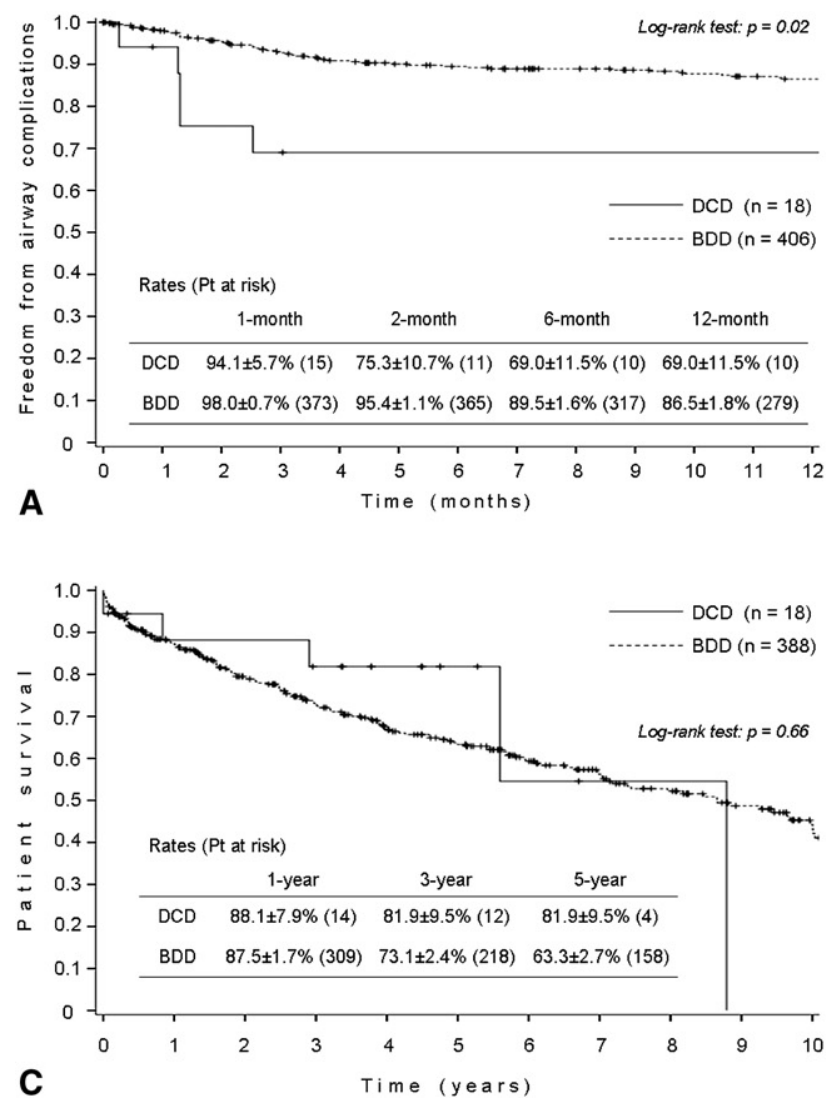

the groups. Figure 2, $B$, shows the freedom from BOS (grades 1,2 , and 3 ) for both groups. The rates of freedom from BOS were not different between the groups $(P=.59)$.

\section{Recipient and Graft Survival}

Recipient and graft survival rates are shown in Figure 2, $C$ and $D$. These survival rates were not different between the
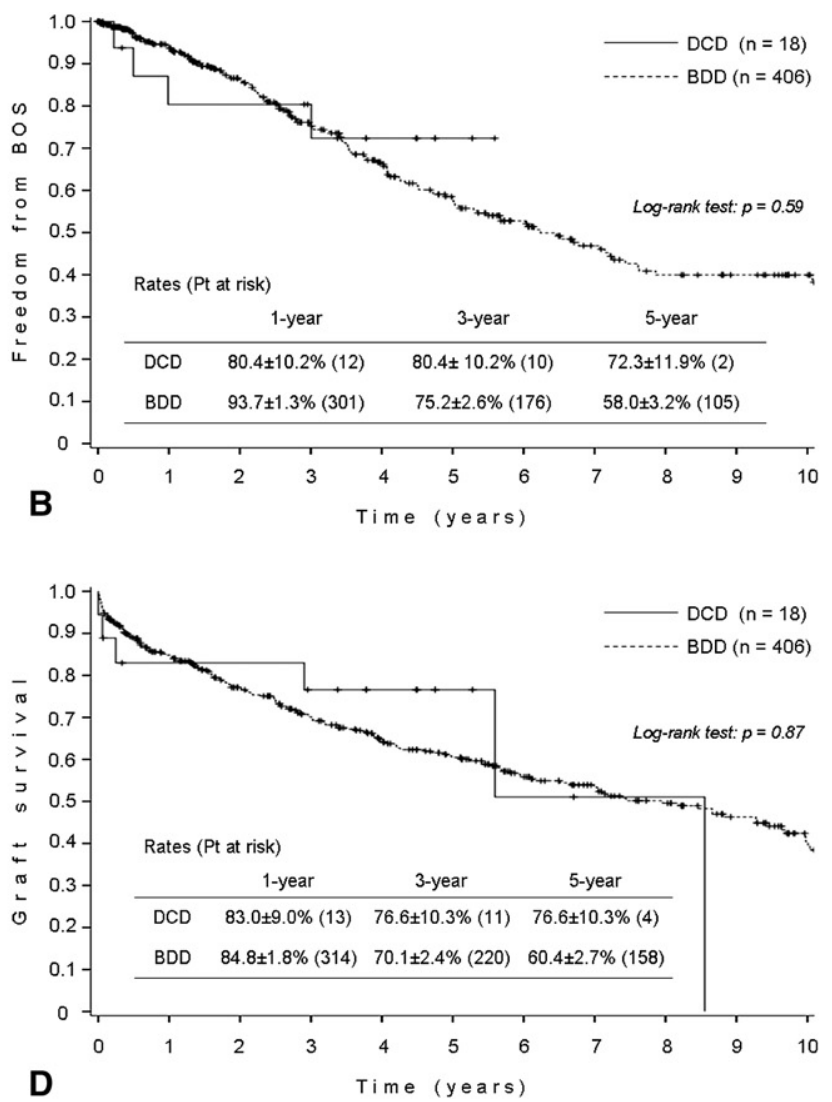

FIGURE 2. A, Freedom from airway anastomotic complications requiring treatment. B, Freedom from bronchiolitis obliterans syndrome (BOS). C, Patient survival. D, Graft survival. $D C D$, Donation after cardiac death; $B D D$, brain-dead donor. 
groups $(P=.66$ for patient survival and $P=.87$ for graft survival). In the DCD group 5 patients died during the study period. Causes of death were small bowel infarction and multiple system organ failure on POD 1, BOS on POD 305 , metastatic colon cancer after 2.9 years, non-small cell cancer on the native lung after 5.6 years, and multiple system organ failure after 8.8 years, respectively.

\section{DISCUSSION}

Our cohort of 18 consecutive recipients of lung transplants with organs recovered from controlled DCD donors is the largest experience from a single center reported in the literature to date. Our patient and graft survival rates plus posttransplantation pulmonary function were not different for recipients of lungs from DCD donors versus recipients given organs from BDDs. Our longest surviving recipient with functioning lung grafts from a DCD donor is now over 6 years after transplantation, and chronic DCD donor lung graft function (including the prevalence of BOS after transplantation) was equivalent to that of recipients of BDD lungs.

PGD continues to be a significant cause of early morbidity and mortality after LTx regardless of donor type. ${ }^{16}$ According to published small case series using controlled DCD donor lung allografts, the incidence of grade 3 PGD ranged from $13 \%$ to $20 \%$, an incidence that is similar to that seen with BDD LTx. ${ }^{7-9}$ Our results also demonstrate that early DCD donor lung allograft function was good, and the incidence of severe PGD in the DCD donor group was not increased in comparison with that of the allografts from BDDs. None of the DCD donor recipients required postoperative ECMO for graft dysfunction.

The unique physiologic features of the lung might contribute to its tolerance of ischemia. Lung parenchymal cells, unlike those from other solid organs, do not rely solely on perfusion for cellular respiration and could maintain tissue adenosine $5^{\prime}$-triphosphate levels as long as oxygen was supplied. ${ }^{17}$ Van Raemdonck and colleagues ${ }^{18}$ demonstrated that postmortem ventilation added to the viability of lungs during the warm ischemic period by providing alveolar expansion and oxygenation. Neyrinck and coworkers ${ }^{19}$ showed that in an animal model of isolated reperfusion DCD donor lung grafts with 1 hour of WIT were less susceptible to PGD than lungs retrieved after 5 hours of in situ mechanical ventilation after brain death. The time of onset of relevant ischemic allograft injury and the tolerable duration of WIT is unknown. The Madrid group ${ }^{20}$ reported that grade 3 PGD occurred in $27 \%$ of recipients after uncontrolled DCD LTx (mean WIT, 118 minutes), and the 1-year mortality of $31 \%$ suggests that longer ischemic time is directly associated with early poor outcomes.

In our experience the recipients of DCD donor lungs received iNO therapy more frequently than BDD recipients. This could have contributed to better oxygenation during the acute phase after LTx in the DCD group (Figure 1, A). Although increased use of iNO was observed in the DCD group, the incidence of PGD was equivalent in the 2 groups. The decision to use iNO was made based on the clinical assessment that the recipient's condition at the time of transplantation warranted its use to provide the optimal conditions for both the graft and recipient physiology at reperfusion. Inhalation of nitric oxide has been investigated as a potential intervention to prevent the development of significant PGD, given the effects of iNO on pulmonary vasodilation, capillary integrity, and prevention of leukocyte adhesion and platelet aggregation. ${ }^{21}$ In a prospective, randomized, blinded clinical trial, Meade and associates ${ }^{22}$ were not able to show any difference in PGD incidence with prophylactic administration of iNO in the patients receiving transplants from BDDs. No prospective data exist regarding the use of iNO in DCD donor LTx; however, protective effects of iNO after warm ischemia in DCD donor lungs have been reported in the laboratory, as demonstrated by better oxygenation and reduction in ischemia-reperfusion injury. ${ }^{23}$ Further evaluation is necessary to detect and confirm a beneficial effect of iNO in DCD donor LTx.

Airway complications can have a critical effect on outcome. The reported incidence of airway complications varies considerably, from $1.6 \%$ to $33 \%$, but most centers have a $7 \%$ to $18 \%$ rate with an associated mortality of $2 \%$ to $4 \%{ }^{24}$ Although the presence of airway complications does not appear to have a significant effect on survival, airway complications could lead to increased costs and decreased quality of life. In the present study the incidence of airway complications requiring treatments was higher in the DCD group, but no deaths occurred as a consequence of airway complications. This airway complication was likely due to technical failure and not ischemia. All other airway issues were minor and were managed endoscopically, generally as outpatients, by one surgeon, and none of these patients required reoperation. The number of patients in this series does not permit further conclusions regarding a direct relationship between WIT in DCD donor LTx and airway complications. The increased incidence of even minor airway complications in the DCD group does raise concern regarding the effect of warm ischemia on bronchial healing. It has been suggested that the central airways might be more susceptible to impaired perfusion and warm ischemia than lung parenchymal cells. Binns and colleagues ${ }^{25}$ found a higher incidence of necrotic changes in a porcine model of LTx at the anastomoses after 21 days in lung transplants from DCD donors after 60 minutes of WIT compared with the incidence for BDDs. The authors suggested that lack of perfusion to the moderate and large airways might contribute to airway ischemic damage after LTx. The use of bronchial clamping during implantation on their animal model might have increased the risk of injury. In contrast, other groups ${ }^{26}$ did not find any difference in bronchial 
healing after DCD donor SLT in rats 5 weeks after the procedure. Clearly, a technically sound bronchial anastomosis in DCD donor lung transplants is no less important than standard donor LTX.

The incidence of A1 acute rejection was lower in our DCD group. The DCD donors have a theoretic benefit in preventing the detrimental effects caused by brain death, such as hemodynamic instability associated with an increase in serum catecholamines, the occurrence of cytokine storm, ${ }^{27}$ and increased organ immunogenicity, as suggested in other solid-organ transplantions. ${ }^{28}$ These potential beneficial effects of using lungs from DCD donors could possibly contribute to improved survival and graft function, as well as a decreased incidence of acute rejection, as observed in current small case series, including our own experience. $^{7-9}$

Chronic graft rejection/BOS remains a major cause of late death for lung transplant recipients. The recent ISHLT report shows that BOS accounts for approximately $30 \%$ of late deaths after primary LTx, and $51 \%$ of lung transplant recipients had BOS within 5 years after primary LTx. ${ }^{29}$ A reasonably accurate determination of the incidence and prevalence of various stages of BOS has yet to be determined for recipients of DCD donor lung transplants. Although our cohort of DCD donor recipients is relatively small, our results suggest that the incidence of BOS is not increased for the DCD donor lungs. Based on our results, it appears that incidence of acute rejection and BOS is no worse in patients undergoing DCD donor LTx.

Mason and colleagues ${ }^{6}$ indicated that the recipients of DCD donor lungs had lower lung allocation scores (LASs; mean LAS, 32) in a recent UNOS data analysis for DCD donor LTx, and they suggested that there was a tendency for DCD donor organs to be given to less ill patients. This could be interpreted as reflecting a bias to use DCD donor organs in patients who are less ill (because of perceived organ inferiority) or patients with relatively low scores because of their recipient indication (eg, diagnosis of severe chronic obstructive pulmonary disease) who are much less likely to receive BDD organs than waitlisted patients with high LASs. Our experience stands in contrast to this observation. It has been our practice to restrict DCD donor LTx to patients deemed too ill to survive the waiting time for BDD donors. After determining LASs, those recipients with disease producing a lower LAS and common blood type that would make it unlikely that they would receive a lung offer within a time frame allowing functional survival on the wait list have also been offered DCD donor lungs. More recipients underwent retransplantation with DCD donor lungs for the pretransplantation diagnosis of graft failure. Six $(33.3 \%)$ patients in the DCD group had pretransplantation hospitalization that exceeded 3 days, and 2 patients required ventilator support before transplantation. One patients with cystic fibrosis in the post-LAS era had an LAS of 90 and was intu- bated for 4 days with severe hemoptysis and partial pressure of carbon dioxide in the 90s, and this patient had previously undergone pleurodesis on the right side. The DCD donor met extended criteria despite a severe contusion on the right side. Successful BLT was performed, and the patient was discharged within 2 weeks with no acute complications. Clearly the use of DCD donors can be used to salvage a patient at high risk of dying while awaiting LTx.

Another finding from the UNOS data analysis was a higher use of BLT procedure in the DCD LTx group. ${ }^{6}$ The authors suggested that the increased use of BLT might have contributed to improved survival in the DCD group. This was not observed in our study in which half the patients underwent SLT, especially in the early experience. In addition, we did not prioritize the use of the BLT procedure for DCD donor lung recipients, and the indication of BLT was identical for both DCD donor and BDD lung recipients.

Although the use of DCD donors has been proposed to expand the donor pool, DCD donor lungs are still seldom used. In fact, the UNOS data show only 36 DCD donor lungs have been used to date, indicating that only $0.2 \%$ of all deceased donors in the past 20 years have been DCD donors. $^{6}$ In our experience this rate was $4.3 \%$ over a 16 -year period.

There are multiple reasons that might explain why the LTx community has been slow to adopt DCD donor LTx. First, the lungs cannot be assessed in situ visually before arrest and perfusion. Second, warm ischemic injury cannot be avoided when DCD donor lung allografts are procured, and therefore the use of DCD donor lungs might increase the risk of PGD and graft failure. Additionally, DCD donor lungs might be more susceptible to aspiration during the time period from extubation to cardiorespiratory arrest. Lastly, the use of DCD donor lungs can raise issues of donor management and procurement that require an increased level of cooperation between organ procurement organization and surgical teams. We believe that the gradual accumulation of experience in DCD donor LTx, including data from centers such as our own, will lead to the recognition of DCD donor lungs as a significant, underused, and safe source of donor lungs.

Limitations of this study include the retrospective analysis of our data. Our clinical data were obtained by means of chart review, which has inherent limitations that include access to and accuracy of the recorded data. Additionally, as a retrospective observational study, it can be subject to selection bias and incomplete data collection. However, the data used in the analysis were all prospectively obtained in our transplantation database for all patients in both the DCD and BDD groups. In the DCD group the number of patients with idiopathic pulmonary fibrosis was small, and these patients are known to have worse survival than most other recipient indications for LTx. This might have led to the

1312 The Journal of Thoracic and Cardiovascular Surgery • May 2010 
perception that outcomes for the DCD donor cohort do not differ significantly in comparison to outcomes for recipients of BDD lungs. Because the number of DCD donor recipients included in the study is small, the analysis of larger cohorts of recipients from other centers or the UNOS database is required to determine whether outcomes for larger numbers of DCD donor recipients differ from our own observations.

Despite the limitations of our data in DCD donor LTx, we view DCD donor LTx as an appropriate procedure for selected recipients. The DCD donor lungs can be particularly useful if BDD organs cannot be obtained for patients with rapid deterioration and high likelihood of mortality if urgent transplantation cannot be performed. Although our observed recipient outcomes with lung transplants from DCD donors have been equivalent to our outcomes for recipients who received lungs from BDDs, additional evaluation of the effect of LTx on various outcome parameters with lungs from DCD donors is needed.

\section{CONCLUSION}

We have reported our 15-year single-center experience in LTx from DCD donors. Our data show that the long-term patient and graft survival rates after DCD donor LTx were equivalent to those after BDD LTx. Although the cohort is small and further evaluation is necessary to confirm our findings, our data suggest that the use of DCD donors can substantially expand the donor pool for LTx. Furthermore, the success of DCD donor LTx will help improve the lung use rate, which remains unacceptably low. The advent of ex vivo perfusion and assessment of lungs now in clinical use in several centers worldwide will substantially improve the ability to use lungs now classified as nonuseable, including DCD donor lungs.

\section{References}

1. Hardy JD, Webb WR, Dalton ML Jr, Walker GR Jr. Lung homotransplantation in man. JAMA. 1963;186:1065-74.

2. Egan TM, Lambert CJ Jr, Reddick R, Ulicny KS Jr, Keagy BA, Wilcox BR. A strategy to increase the donor pool: use of cadaver lungs for transplantation. Ann Thorac Surg. 1991;52:1113-20.

3. D'Alessandro AM, Hoffmann RM, Knechtle SJ, Eckhoff DE, Love RB, Kalayolgu M, et al. Controlled non-heart-beating donors (NHBDs): a potential source of extrarenal organs. Transplant Proc. 1995;27:707-9.

4. Cooper JT, Chin LT, Krieger NR, Fernandez LA, Foley DP, Becker YT, et al. Donation after cardiac death: the University of Wisconsin experience with renal transplantation. Am J Transplant. 2004;4:1490-4.

5. Foley DP, Fernandez LA, Leverson G, Chin LT, Krieger N, Cooper JT, et al. Donation after cardiac death: the University of Wisconsin experience with liver transplantation. Ann Surg. 2005;242:724-31.

6. Mason DP, Thuita L, Alster JM, Murthy SC, Budev MM, Mehta AC, et al. Should lung transplantation be performed using donation after cardiac death? The United States experience. J Thorac Cardiovasc Surg. 2008;136:1061-6.

7. Snell GI, Levvey BJ, Oto T, McEgan R, Pilcher D, Davies A, et al. Early lung transplantation success utilizing controlled donation after cardiac death donors. Am J Transplant. 2008;8:1282-9.
8. De VS, Van RD, Vanaudenaerde B, Vos R, Meers C, Wauters S, et al. Early outcome after lung transplantation from non-heart-beating donors is comparable to heart-beating donors. J Heart Lung Transplant. 2009;28:380-7.

9. Mason DP, Murthy SC, Gonzalez-Stawinski GV, Budev MM, Mehta AC, McNeill AM, et al. Early experience with lung transplantation using donors after cardiac death. J Heart Lung Transplant. 2008;27:561-3.

10. Christie JD, Carby M, Bag R, Corris P, Hertz M, Weill D. Report of the ISHLT working group on primary lung graft dysfunction. Part II: definition. A consensus statement of the International Society for Heart and Lung Transplantation. J Heart Lung Transplant. 2005;24:1454-9.

11. D'Alessandro AM, Fernandez LA, Chin LT, Shames BD, Turgeon NA, Scott DL, et al. Donation after cardiac death: the University of Wisconsin experience. Ann Transplant. 2004;9:68-71.

12. Rosengard BR, Feng S, Alfrey EJ, Zaroff JG, Emond JC, Henry ML, et al. Report of the Crystal City Meeting to maximize the use of organs recovered from the cadaver donor. Am J Transplant. 2002;2:701-11.

13. Talbot D, D'Alessandro AM, Love RB, Wigfield C, Dark J. Lung transplantation from non-heart beating donors-donation after cardiac death (DCD). In: Talbot D, D'Alessandro A, eds. Organ donation and transplantation after cardiac death. Oxford, United Kingdom; 2008:232-53.

14. Institute of Medicine DoHCS. Non-heart-beating organ transplantation. In: Herdman R, Potts JT, eds. Medical and ethical issues in procurement. Washington, DC: National Academy Press; 1997.

15. Yousem SA, Berry GJ, Cagle PT, Chamberlain D, Husain AN, Hruban RH, et al. Revision of the 1990 working formulation for the classification of pulmonary allograft rejection: Lung Rejection Study Group. J Heart Lung Transplant. 1996;15:1-15.

16. Meyers BF, de la MM, Sweet SC, Trulock EP, Guthrie TJ, Mendeloff EN, et al. Primary graft dysfunction and other selected complications of lung transplantation: a single-center experience of 983 patients. J Thorac Cardiovasc Surg. 2005; $129: 1421-9$.

17. Koukoulis G, Caldwell R, Inokawa H, Button B, Sevala M, Lyles JD, et al. Trends in lung $\mathrm{pH}$ and $\mathrm{PO} 2$ after circulatory arrest: implications for non-heart-beating donors and cell culture models of lung ischemia-reperfusion injury. $J$ Heart Lung Transplant. 2005;24:2218-25.

18. Van Raemdonck DE, Rega FR, Neyrinck AP, Jannis N, Verleden GM, Lerut TE. Non-heart-beating donors. Semin Thorac Cardiovasc Surg. 2004;16:309-21.

19. Neyrinck AP, Van De WC, Geudens N, Rega FR, Verleden GM, Wouters P, et al Comparative study of donor lung injury in heart-beating versus non-heart-beating donors. Eur J Cardiothorac Surg. 2006;30:628-36.

20. de Antonio DG, Marcos R, Laporta R, Mora G, Garcia-Gallo C, Gamez P, et al Results of clinical lung transplant from uncontrolled non-heart-beating donors. J Heart Lung Transplant. 2007;26:529-34.

21. Shargall Y, Guenther G, Ahya VN, Ardehali A, Singhal A, Keshavjee S. Report of the ISHLT Working Group on Primary Lung Graft Dysfunction part VI: treatment. J Heart Lung Transplant. 2005;24:1489-500.

22. Meade MO, Granton JT, Matte-Martyn A, McRae K, Weaver B, Cripps P, et al. A randomized trial of inhaled nitric oxide to prevent ischemia-reperfusion injury after lung transplantation. Am J Respir Crit Care Med. 2003;167:1483-9.

23. Takashima S, Koukoulis G, Inokawa H, Sevala M, Egan TM. Inhaled nitric oxide reduces ischemia-reperfusion injury in rat lungs from non-heart-beating donors. J Thorac Cardiovasc Surg. 2006;132:132-9.

24. Santacruz JF, Mehta AC. Airway complications and management after lung transplantation: ischemia, dehiscence, and stenosis. Proc Am Thorac Soc. 2009;6: 79-93.

25. Binns OA, DeLima NF, Buchanan SA, Nichols GE, Cope JT, King RC, et al. Impaired bronchial healing after lung donation from non-heart-beating donors. J Heart Lung Transplant. 1996;15:1084-92.

26. Wierup P, Andersen C, Janciauskas D, Bolys R, Sjoberg T, Steen S. Bronchia healing, lung parenchymal histology, and blood gases one month after transplantation of lungs topically cooled for 2 hours in the non-heart-beating cadaver. J Heart Lung Transplant. 2000;19:270-6.

27. Avlonitis VS, Fisher AJ, Kirby JA, Dark JH. Pulmonary transplantation: the role of brain death in donor lung injury. Transplantation. 2003;75: 1928-33.

28. Sanchez-Fructuoso A, Naranjo GP, Calvo RN, Ridao N, Naranjo GP, Conesa J, et al. Effect of the brain-death process on acute rejection in renal transplantation. Transplant Proc. 2007;39:2214-6.

29. Christie JD, Edwards LB, Aurora P, Dobbels F, Kirk R, Rahmel AO, et al. Registry of the International Society for Heart and Lung Transplantation: twenty-fifth official adult lung and heart/lung transplantation report-2008. J Heart Lung Transplant. 2008;27:957-69. 


\section{Discussion}

Dr Dirk E. M. Van Raemdonck (Leuven, Belgium). I would like to thank Dr Osaki and colleagues for a clear presentation reporting an in-depth analysis of the late outcomes in a cohort of 18 lung transplant recipients from so-called Maastricht Category III controlled non-heart-beating donors. The LTx group at the University of Wisconsin is to be congratulated with this largest and longest single-center series on LTx from DCD donors reported thus far. The experience of the group dates back to 1993, when Bob Love got interested and started the use of lungs from this type of donor in whom other organs, like the kidney, liver, and pancreas, were already recovered for transplantation at Madison.

The authors conclude that the long-term patient and graft survival in lung transplant recipients from donors after cardiac death are equivalent to those from donors after brain death and that these donors therefore could be safely used to expand the donor pool. Nevertheless, the reported doubled incidence of bronchial complications in these recipients might be a concern that should be further investigated.

I have 3 questions for the presenter that I will pose one at a time.

The authors define the WIT as the period between the withdrawal of life support, extubation, and the start of cold perfusion, on average about 30 minutes. In my opinion this definition is not entirely correct because in some donors spontaneous breathing continues after extubation and the blood pressure remains sufficient to perfuse the organs for a longer period of time, and therefore the lungs cannot be considered as being ischemic already. To compare results between different institutions across the world and to enter data in an international register, such as the one from the ISHLT, we should agree on the same definition of warm ischemia: either from cardiac arrest until cold flush perfusion or when the blood pressure in the donor decreases to less than $50 \mathrm{~mm} \mathrm{Hg}$. Therefore my question is this: Can the authors comment on this definition and also provide us with the exact time between cardiac arrest or electromechanical dissociation and the start of cold perfusion?

Dr Osaki. Thank you very much, Professor Van Raemdonck, for your kind comments and the question about the appropriate definition of WIT. Dr Snell and colleagues, the group from Australia, suggested in a recent publication that the definition of WIT should be considered as the interval between starting at a systolic blood pressure of less than $50 \mathrm{~mm} \mathrm{Hg}$ and the initiation of cold flush preservation of the organs for controlled DCD donors. We agree with this definition. In our organ procurement organization, since 2006, the changes in hemodynamics from extubation to cardiac arrest are recorded. However, 15 of 18 cases DCD donor LTx were performed before that time, and the data were not documented. Thus we were not able to obtain records of the hemodynamic changes during the time between extubation and declaration of death on most DCD donors. In terms of the exact time between cardiac arrest and cold flush of preservation solution, the mean time was 9 minutes.

Dr Van Raemdonck. All donors were extubated in the operating room, and some donors were returned to the ward if cardiac arrest did not occur within 2 hours after withdrawal of support. Can the authors tell us what percentage of organs could not be recovered from these potential donors and whether they believe that any sedative drugs could be given to improve the donor's comfort and relieve the family from further awaiting the inevitable death in the hours thereafter?
Dr Osaki. During the study period, from January 1993 to April 2009, 269 DCD donor procurements were performed in our local organ procurement organization. From those, 18 DCD donor lungs were used, indicating a lung recovery rate of $6.7 \%$. Although we tried, we could not identify the number of potential DCD donors in which cardiac arrest did not occur and were returned to the intensive care unit or hospital ward. In addition, the total number of DCD donor offers made to our program was not available from our database. In terms of care of DCD donor candidates, I cannot make any comments about the use of sedative drugs or end-oflife management for those DCD donor candidates; however, I am sure those were applied by the physicians managing the donor candidates.

Dr Van Raemdonck. Finally, the freedom from airway complications was significantly lower in recipients of organs from DCD donors. This raises the question of whether the additional warm ischemic interval contributes to the damage of the larger airways subjected to impaired healing. The use of an additional retrograde pulmonary flush delivered through the 4 pulmonary veins is believed to preserve the bronchial tree better through collateral perfusion of the bronchial arteries. Did your group at Wisconsin implement such a retrograde flush in your DCD donors, and if so, was this equally compared between both groups?

Dr Osaki. We appreciate your suggestion on a possible method to prevent airway complications in the DCD donor lung grafts. The possibility of increased airway complications deserves further investigation. About the specific question regarding the use of retrograde flush to the pulmonary veins, I can say that this has been part of our routine technique of lung graft recovery. In an animal study with a pig model, Binns and colleagues suggested that central airways might be more susceptible to the lack of perfusion during ischemia than lung parenchymal cells, which can maintain some aerobic metabolism through ventilation. Certainly the effects of warm ischemia on bronchial healing deserve further investigation.

Dr Van Raemdonck. Once again, I congratulate you on a nice presentation. Thank you.

Dr Love. Dirk, I can help with some of those question because in point of fact, none of the authors were involved primarily with any of these cases except for the case of bronchial dehiscence. That bronchial dehiscence, which I repaired myself, was a technical problem and not ischemia as reported here. None of the other bronchial problems in the initial 17 patients were a major problem for the patient and were managed bronchoscopically without significant morbidity.

The development of DCD donor LTx as a clinical reality during my tenure at the University of Wisconsin was adopted over many years. It has been gratifying to see the adoption of the techniques of donor management and selection, recipient selection, and validation of my results at many centers in Europe, North America, and Australia. Retrograde flush at procurement was used in all patients, and over the years, there was about $30 \%$ occurrence of nonretrieval of lungs when going out for procurement.

Dr Bryan F. Meyers (St Louis, Mo). I think this is something that is a great idea in principle, but when it gets down to the specifics, it becomes more challenging to evaluate. When Dr Love started doing this, I am sure he was extremely selective about the DCD donors that he accepted and the interaction between the DCD donor and the risk of the recipient the lung was going into. 
When I evaluate an offer from a potential DCD donor, I will weigh the quality of the donor lung and then look at potential recipients for one that is suitable. I also consider the distance and the likely length of ischemic time. There are a lot of factors that we have already put into the decision making that would help make this work out, and presenting this without knowing the bias behind all those careful selections would perhaps make this look equivalent when it is really not as equivalent as it might seem. I agree with more data collection to learn more about the decision making and the other unrecorded factors, but these are great results, and they make DCD donors appear equivalent, but I think that there were a lot of accommodations that were made to make DCD donors work out as well as possible in the beginning.

Dr John H. Dark (Newcastle, United Kingdom). I would like to echo what others have said about the role of Bob Love in both originating this field and driving this particular series of patients forward.

My question is about the PGD incidence and the use of nitric oxide. You have clearly put a huge amount of work into collecting these data over the years. Your PGD incidence would perhaps seem a little higher than that been recorded in European and Australian series, although the numbers are all small. Was there any correlation between any of the preoperative variables in terms of WIT or cold ischemic time and PGD?

Dr Osaki. Thank you very much for your question.

Actually we did analyze the correlation between the WIT or cold ischemic time and the incidence of airway complications; however, there was no correlation between these parameters.

Dr De Oliveira. With regard to Dr Meyers' comments, before we start the indiscriminate use of DCD donor lungs, I think we have to be very careful because the definition of WIT is not yet very clear. It goes from a few minutes in countries in which euthanasia is allowed to as long as 90 minutes, as in one of the patients in our series. There is no question that there is a selection bias as well. Most DCD donor lungs meet standard criteria. I do not think there is that much experience about the use of extended criteria or marginal DCD donor lungs.

Having said that, I think this is an extremely important technique. In many situations I believe DCD donor lungs have been used as a salvage procedure, and I do not think those patients would have received a lung transplant on time if they had to wait for a BDD.

Finally, I think there is a lot of potential in the future to combine the use of the ex vivo lung perfusion system and the use of DCD donor organs. DCD donor organs could potentially be evaluated before LTx.

Dr Shaf Keshavjee (Toronto, Ontario, Canada). If I can follow up on that, we have done about 11 or 12 DCD organ transplantations and because we have the ex vivo trial going, we have made it a policy to do ex vivo assessment of all of the DCD donor lungs in our program before implanting them to learn a little bit more about the process. DCD donor lungs in many cases could in fact be better organs and not exposed to the ravages of inflammatory injury of brain death and brain stem coning and so on, but on the other hand, if death or cessation of circulation occurs slowly, you can go through an agonal phase of low blood pressure and shock with the possibility of developing a shock lung. Therefore it might well be a less predictable organ source. I do think that the ability to be able to assess the lung before you implant it might help us to define which organs are going to be usable.

Dr Bartosz Kubisa (Szczecin, Poland). Thank you for your nice presentation.

The good results that you have received with these donors, are they far away from those of the non-heart-beating donors? Can we also have the same good results in the future from the nonheart-beating donors? What is the time difference in the case of your donors and the patients when the heart actually stopped and the explantation of lungs is after an hour or 2 or a longer period of time?

To clarify, I understand you are referring to category I and II donors in whom cardiac activity has already stopped? I guess the question is this: Do you expect to get equivalently good results with Maastricht category I and II donors as you have achieved with the category III donors?

Dr Osaki. I do not think so.

Dr Keshavjee. I think that that is another area of interest; obviously Steen has looked at it, and Dirk Van Raemdonck and others have explored this area as well. Andres Varela in Madrid has performed transplantations in a number of patients. There is no doubt that the category I and II donor lungs have a much more significant PGD and a lower 1-year survival than what has been published worldwide with BDDs. Once again, those are lungs that have taken a bigger hit, and I think again that there might be some good organs in that group, but there is more variability, and that speaks again for the advantage of the ability to be able to test or recondition the lungs before you implant them.

Dr Waleed Saleh (Riyadh, Saudi Arabia). You mentioned that the airway complications after DCD donor LTX were higher?

Dr Osaki. Yes.

Dr Saleh. What were they specifically, more dehiscence or stenosis or infection?

Dr Osaki. Actually, we had 5 airway complications. One had ischemic bronchial dehiscence on POD 8, but the other 4 patients had bronchial stenosis, and 2 of them had an Aspergillus species infection.

Dr Stephen D. Cassivi (Rochester, Minn). I have a quick comment. I think Bob Love and his group are to be congratulated once more. This is especially true in this day and age of tremendous transparency in transplantation in North America and when in the United States every outcome is on the Internet within 6 months. In transplantation our outcomes are scrutinized very, very closely. This has a real potential to stifle innovation such as this. Therefore for Dr Love to move forward with something like this is a testament to his ability to take on risk and manage it successfully. Congratulations.

Dr Osaki. Thank you very much.

Dr Keshavjee. I think that is exactly what Tom Spray was alluding to in his Presidential Address. Congratulations again, Bob. 